\title{
Nasofrontal Complex Variation Frontal Sinus Drainage System Increases Frontal Rhinosinusitis Incident
}

\author{
Abdul Qadar Punagi ${ }^{1, *}$ \\ ${ }^{1}$ Department of Ear, Nose and Throat, Faculty of Medicine, Hasanuddin University, Jl. Perintis Kemerdekaan Km.10, Makassar, Indonesia \\ *Corresponding author. E-mail: qa_dar@yahoo.co.id
}

Received date: Jun 3, 2015; Revised date: Oct 7, 2015; Accepted date: Oct 19, 2015

\section{Abstract}

$\mathrm{B}$ ACKGROUND: This research was conducted to find out the relation of anatomy variation of nasofrontal complex on the frontal sinus drainage system with frontal rhinosinusitis incident.

METHODS: This research was using cross-sectional design involving 75 patients with chronic rhinosinusitis. Coronal paranasal sinus CT scan with sagittal plane reformat was carried out to examine. The CT scan figures were analyzed from every side and there were 150 samples found as the result. Data was analyzed using chi square test.

RESULTS: The research indicates that there is no significant relation between frontal cell types, agger nasi cell, chonca media bullosa with incident of frontal rhinosinusitis $(p>0.05)$. Prevalence of superior attachment of uncinate process (UP), type 1 (UP superior attachment on lamina papiracea) was found on 43 sides (28.6\%), type 6 (UP superior attachment to medial turbinate) was found in 29 sides (19.3\%). Prevalence of frontal rhinosinusitis was found in $42(28 \%)$ from 150 sides. Group 1 drainage (medial side drainage; drainage to meatus medius [type 1-3]) was found in 32 sides (76.2\%) and group 2 drainage (lateral side drainage; drainage to infundibulum ethmoid [type 4-6]) was found in 10 sides $(23.8 \%)$.

CONCLUSION: There is significant relation between frontal rhinosinusitis incident with variation of frontal sinus drainage $(p<0.05)$ and drainage on group 1 has significant existence statistically on frontal rhinosinusitis incident.

KEYWORDS: frontal rhinosinusitis, anatomy variation, nasofrontal complex, frontal sinus drainage

Indones Biomed J. 2016; 8(1): 49-54

\section{Introduction}

Frontal rhinosinusitis is an infection that tends to worse with tendencies developed of intracranial spread, but intracranial complications of frontal sinusitis is very rare. Several factors have been discussed regarding the pathogenesis of chronic frontal rhinosinusitis. There are some cells which are classified as cells that can lead to obstruction of the frontal recess and frontal rhinosinusitis causes. Frontal recess cells include agger nasi cell, supraorbital ethmoid cells, frontal cells, frontal bulla cell, suprabullar cell and interfrontal septal sinus cells.(1)
In addition to anatomical obstruction, obstruction of the frontal recess mucosa plays an important role in the occurrence of chronic frontal rhinosinusitis. Also, there are different factors such as hypoxia, dehydration, infection, foreign body, environmental irritants, trauma, tumors and allergens that can affect physiological functions by interfering with the function of the frontal sinus cleansing by mucocilliary clearance.(2)

The drainage system of the frontal sinus depends on anatomical variations as the nasofrontal complex consisting of the frontal sinus, frontal recess and structures in and around it, which is part of the frontal recess and the superior anterior ethmoid sinus associated with frontal sinus recess 
anatomy.(3) Complexity with multiple anatomic variations surrounding the frontal recess which can cause blockage of the flow of frontal sinus. The complexity of anatomical variations in the cells around the frontal recess cells can be frontal, agger nasi cells, ethmoid bulla, the convergence of uncinate process (UP), and turbinate bullosa. These structures form walls and bottom of the frontal recess. The lateral wall of the frontal recess is lamina papyracea, medial wall by the vertical media turbinate (the most anterior and superior), the anterior wall is agger nasi cell, the posterior wall is ethmoid bulla.(4,5)

Frontal cells is air cavity which is round or oval located at the anterior frontal recess, in the inferior part of the frontal sinus, which is related to the agger nasi air cavity. Frontal cells are divided into four types as follows: frontal type I cells, there is a single cell in the upper frontal agger nasi cells; frontal type II cells, there are two cells in the upper frontal agger nasi cells; frontal type III cells, cells located above the agger nasi cell that extends to the superior frontal recess through the frontal ostium and into the frontal sinus; and frontal cells of type IV frontal cell that is not adjacent to the agger nasi cells, the isolated cells in the frontal sinus.

Agger nasi cell and UP form the basis of flow in the frontal recess. Frontal recess can be tapered at the anteroinferior due to hyper-agger nasi cell pneumatization. If the UP attached to the lamina papyracea, lateral orbit, the frontal recess opens directly into the superior aspect of the superior medial meatus.(5) UP attachment is an important anatomical structures in the frontal recess region. Classification of two types of frontal sinus flow systems are medial or lateral region of UP.(1)

Stenosis of the nasofrontal complex appeared mostly due to three reasons. First, inadequate removal of agger nasi and frontal cells resulting in adhesion and scarring. Secondly, excessive dissection in the frontal recess including releasing mucous layer will cause osteogenesis and stenosis of nasofrontal complex. Third, excessive removal of medial turbinate can lead to increased incidence of frontal recess stenosis and lateralization.(6)

Therefore the aim of this study was to determine the relationship of nasofrontal complex anatomical variations of the frontal sinus drainage system with rhinosinusitis incidence that was obtained from the frontal sinus CT scan images. The result of present research can be a reference for operators of functional endoscopic sinus surgery when performs frontal sinusotomy.

\section{Methods}

This was a cross sectional study conducted in the department of Ear, Nose, Throat (ENT) clinic of Dr. Wahidin Sudirohusodo in January to June 2014. Ethical approval for this study was released by the Ethics Committee of Human Protection in Biomedical Research, Faculty of Medicine, Hasanuddin University, number 1705/H4.8.4.5.31/PP36KOMETIK/2013.

The study population was patients with chronic rhinosinusitis who came for treatment. The samples were rhinosinustis patients who met the inclusion criteria and also willing to participate in the study. The inclusion criteria were patients with clinical symptoms of chronic rhinosinusitis based on clinical symptoms, physical examination according to the criteria of the ENT task force examination and CT scan, the general state of the patient may undergo a CT scan of the paranasal sinuses coronal plane with a prone position. Samples were excluded if the patients have a history of sinonasal surgery, sinonasal tumors, nasal polyps, nasal trauma and invasive fungal sinusitis. The total sample of 75 patients with chronic rhinosinusitis who had given pharmacological therapy and then examined for CT scan of the paranasal sinuses coronal plane with sagittal reformatted that are planned for functional endoscopic sinus surgery. CT scan without contrast, coronal plane, with $3 \mathrm{~mm}$ thick slices, then the data was reconstructed for volumetric CT coronal and sagittal planes to slices with a thickness of $1 \mathrm{~mm}$ by a computer program. Each side of the nasofrontal complex (agger nasi cells, frontal cell type, medial turbinate bullosa and superior adhesion of UP and the frontal sinus drainage system was evaluated separately in order to obtain 150 sides.

Rhinosinusitis was observed by a CT scan of the paranasal sinuses. Patients suffer from rhinosinusitis when at paranasal sinus CT scan obtained the frontal sinus mucosal thickening were assessed on each side of the sinus according to the score "Lund Mackay" ( 0 : There is no abnormality, 1: partial, 2: total). In this study, partial and total frontal sinus mucosal thickening are combined.

UP superior attachment is a plate of bone and important anatomical structure in the region of the frontal recess. Six types of superior UP attachment with CT scan are: Type 1: insertion of UP into the lamina papyracea, Type 2: UP 
insertion into the posterior wall of agger nasi cell and into the lamina papyracea, Type 3: UP insertion into the lamina papyracea and relationships of the medium turbinate with cribriform plate, type 4: UP insertion from media turbinate relation to the cribriform plate, type 5: UP insertion into the base of the skull, type 6: UP insertion into turbinate media. Localization of the frontal sinus drainage system was determined according to the attachment of the superior UP on CT scans, those are: Group 1: Drainage medial side; frontal sinus drainage at the meatus medius (medial to the superior attachment of the UP [types 1-3]), Group 2: Drainage lateral side; drainage of the frontal sinus to the ethmoid infundibulum (lateral to the superior attachment of the UP [types 4-6]).

The data were grouped by the type of data collected and processed using a computerized data processing system. Statistical tests performed using chi square linear by linear association test. The test results were considered significant if $p<0.05$. The results obtained are shown in the form of narrative, tables and graphs below.

\section{Results}

In this study, samples were obtained from 75 patients. By gender, there were 35 male patients $(46.7 \%)$ and 40 female patients $(53.3 \%)$, with a ratio of men:female $1: 1.14$. The number of samples from each age group is almost the same, most of it are in the age group 15-20 years old (22.7\%) (Table 1).

The data showed that of 150 each side of the nasofrontal complex cell structure, the most is frontal cell type 1, with 74 sides (49.3\%), then type 2 frontal cells were 39 sides (26.0\%), frontal cell type 3 is 30 sides $(20.0 \%)$ and

Table 1. Distribution by sex, age group.

\begin{tabular}{ccc}
\hline Characteristic & Frequency & Percentage (\%) \\
\hline Sex & & \\
Male & 35 & 46.7 \\
Female & 40 & 53.3 \\
Total & $\mathbf{7 5}$ & $\mathbf{1 0 0}$ \\
\hline Age (year) & & \\
$15-20$ & 17 & 22.7 \\
$21-30$ & 12 & 16 \\
$31-40$ & 15 & 20 \\
$41-50$ & 15 & 20 \\
$51-60$ & 16 & 21.3 \\
Total & $\mathbf{7 5}$ & $\mathbf{1 0 0}$ \\
\hline
\end{tabular}

at least type 4 of frontal cells were 7 sides (4.7\%) (Table 2). The presence of the media concha bullosa is $15.3 \%$. Distribution of the superior attachment type of UP, namely type 1 UP superiorly were mostly papyracea lamina with 43 sides $(28.6 \%)$, then the type 6 of the attachment of the superior UP to turbinate media as much as 29 sides (19.3\%). While type 3 and type 5 is very rare. Drainage of the superior attachment type based UP in group 1 (type 1, 2, 3) the drainage of the frontal sinus meatus medius (medial to the superior attachment of the UP) is the most frequent, found in 81 sides $(54.0 \%)$. Whereas in group 2 (type $4,5,6$ ) that drainage from the frontal sinus to the ethmoid infundibulum (lateral to the superior attachment of the UP) is found as many as 69 sides $(46.0 \%)$.

Table 2. Distribution of frontal rhinosinusitis, variation of frontal cell type, media concha bullosa, variations of UP attachment type and the type of frontal sinus drainage based on evaluation of paranasal sinus CT scan on each side.

\begin{tabular}{|c|c|c|}
\hline Characteristic & $\begin{array}{l}\text { Frequency } \\
\text { Each Side }\end{array}$ & $\begin{array}{c}\text { Percentage } \\
(\%)\end{array}$ \\
\hline \multicolumn{3}{|c|}{ Rhinosinusitis frontal } \\
\hline Exist & 42 & 28 \\
\hline Not Exist & 108 & 72 \\
\hline Total & 150 & 100 \\
\hline \multicolumn{3}{|l|}{ Frontal cell type } \\
\hline Type 1 & 74 & 49.3 \\
\hline Type 2 & 39 & 26 \\
\hline Type 3 & 30 & 20 \\
\hline Type 4 & 7 & 4.7 \\
\hline Total & 150 & 100 \\
\hline \multicolumn{3}{|c|}{ Concha media bullosa } \\
\hline Exist & 23 & 15.3 \\
\hline Not Exist & 127 & 84.7 \\
\hline Total & 150 & 100 \\
\hline \multicolumn{3}{|c|}{ Superior UP attachment } \\
\hline Type 1 & 43 & 28.6 \\
\hline Type 2 & 27 & 18 \\
\hline Type 3 & 10 & 6.7 \\
\hline Type 4 & 28 & 18.7 \\
\hline Type 5 & 13 & 8.7 \\
\hline Type 6 & 29 & 19.3 \\
\hline Total & 150 & 100.1 \\
\hline \multicolumn{3}{|c|}{ Drainage sinus frontal } \\
\hline Group 1 & 81 & 54 \\
\hline Group 2 & 69 & 46 \\
\hline Total & 150 & 100 \\
\hline
\end{tabular}


There were 42 sides (28\%) samples with frontal rhinosinusitis. The data showed a total of 24 sides (57.1\%) who suffered from frontal rhinosinusitis has a frontal cell type 1 , followed by type 2 with $21.4 \%$, type 3 with $16.7 \%$ and type 4 with $4.8 \%$ (Table 3 ). The results of the statistical test $($ chi square test) $\mathrm{p}$ value $=0.363(p>0.05)$, which showed no significant relationship between the variation of frontal cell types with events of frontal rhinosinusitis. The presence of the media concha bullosa also found no significant correlation with the incidence of frontal rhinosinusitis with $p=0.523(p>0.05)$, as well as the presence of agger nasi cells was also not found a statistically significant association with the incidence of frontal rhinosinusitis with $\mathrm{p}=0.289$ $(p>0.05)$.

Variations of the UP superior attachment type which most experienced frontal rhinosinusitis is type 1 (52.4\%), followed by type $2(14.3 \%)$, type $4(11.9 \%)$, type $3(9.5 \%)$, type $6(7.1 \%)$ and the least amount of type $5(4.8 \%)$. The results of the statistical test (chi square linear by linear association test) $p=0.000 \quad(p<0.05)$ which indicates a significant relation between the various types of attachment UP with frontal rhinosinusitis events.

Table 3. Relationship of nasofrontal complex; agger nasi cells, frontal cell type, media concha bullosa and superior adhesion of UP with frontal rhinosinusitis events.

\begin{tabular}{|c|c|c|c|}
\hline \multirow{2}{*}{ Nasofrontal Complex } & \multicolumn{2}{|c|}{ Rhinosinusitis Frontal } & \multirow{2}{*}{$p$} \\
\hline & Exist & Not Exist & \\
\hline \multicolumn{4}{|l|}{ Frontal cell type } \\
\hline Type 1 & $24(57.1 \%)$ & $50(46.3 \%)$ & \multirow{5}{*}{0.363} \\
\hline Type 2 & $9(21.4 \%)$ & $30(27.8 \%)$ & \\
\hline Type 3 & $7(16.7 \%)$ & $23(21.3 \%)$ & \\
\hline Type 4 & $2(4.8 \%)$ & $5(4.6 \%)$ & \\
\hline Total & $42(100 \%)$ & $108(100 \%)$ & \\
\hline \multicolumn{4}{|l|}{ Concha media bullosa } \\
\hline Exist & $6(14.3 \% \%)$ & $17(15.7 \%)$ & \multirow{3}{*}{0.523} \\
\hline Not Exist & $36(85.7 \%)$ & $91(84.3 \%)$ & \\
\hline Total & $42(100 \%)$ & $108(100 \%)$ & \\
\hline \multicolumn{4}{|l|}{ Agger nasi cell } \\
\hline Exist & $40(95.2 \%)$ & $97(89.8 \%)$ & \multirow{3}{*}{0.289} \\
\hline Not Exist & $2(4.8 \%)$ & $11(10.2 \%)$ & \\
\hline Total & $42(100 \%)$ & $108(100 \%)$ & \\
\hline \multicolumn{4}{|l|}{ Superior UP attachment } \\
\hline Type 1 & $22(52.4 \%)$ & $21(19.4 \%)$ & \multirow{7}{*}{$\mathbf{0}$} \\
\hline Type 2 & $6(14.3 \%)$ & $21(19.4 \%)$ & \\
\hline Type 3 & $4(9.5 \%)$ & $6(5.6 \%)$ & \\
\hline Type 4 & $5(11.9 \%)$ & $23(21.3 \%)$ & \\
\hline Type 5 & $2(4.8 \%)$ & $11(10.2 \%)$ & \\
\hline Type 6 & $3(7.1 \%)$ & $26(24.1 \%)$ & \\
\hline Total & $42(100 \%)$ & $108(100 \%)$ & \\
\hline
\end{tabular}

The variation of the frontal sinus drainage group 1 (open frontal sinus medial to the UP [types 1-3]) more often causing frontal rhinosinusitis as many as 32 sides $(76.2 \%)$, while drainage group 2 (frontal sinus opens lateral to UP [types 4-6]) found 10 sides (23.8\%) (Table 4). The results of the statistical test (chi square linear by linear association test) $p=0.001 \quad(p<0.05)$ which showed a significant association between variation in the incidence of frontal sinus drainage frontal rhinosinusitis.

Table 4 Frontal sinus drainage type relationship with the incidence of frontal rhinosinusitis.

\begin{tabular}{ccccc}
\hline \multirow{2}{*}{$\begin{array}{c}\text { Rhinosinusitis } \\
\text { Frontal }\end{array}$} & \multicolumn{2}{c}{ Drainage Type } & \multirow{2}{*}{ Total } \\
\cline { 2 - 4 } & & Group 1 & Group 2 & \\
\hline \multirow{2}{*}{ Exist } & $\mathrm{n}$ & 32 & 10 & 42 \\
& $\%$ & $76.20 \%$ & $23.80 \%$ & $100.00 \%$ \\
\multirow{2}{*}{ Not Exist } & $\mathrm{n}$ & 49 & 59 & 108 \\
& $\%$ & $45.40 \%$ & $54.60 \%$ & $100.00 \%$ \\
\multirow{2}{*}{ Total } & $\mathbf{n}$ & $\mathbf{8 1}$ & $\mathbf{6 9}$ & $\mathbf{1 5 0}$ \\
& $\mathbf{\%}$ & $\mathbf{5 4 . 0 0 \%}$ & $\mathbf{4 6 . 0 0 \%}$ & $\mathbf{1 0 0 . 0 0 \%}$ \\
\hline
\end{tabular}

\section{Discussion}

The number of samples that met the inclusion criteria were as many as 75 subjects with chronic rhinosinusitis symptomps. The patients were examined and evaluated by CT scan of the frontal sinus on both sides in order to obtain 150 samples.

Age range in this study were 15-60 years old with the average of 36.4. The highest frequency is in the age group of 15-20 years old. In accordance with the literature that the frontal sinus begins to develop at age 8-10 years and reach the maximum size before the age of 20 years. Frequency of sex the subject of men and women are almost equal.

The evaluation of overall frontal cells (Table 2) was found that most are type 1 frontal cell is (49.3\%), then type 2 frontal cells were $(26.0 \%)$, type 3 frontal cell as much $(20.0 \%)$ and are at least as many type 4 frontal cell (4.7\%). Nevertheless, there were no significant frontal cells on the incidence of frontal rhinosinusitis $(p>0.05)$. This suggests that the incidence of frontal rhinosinusitis is not determined by the presence of frontal cells. The results of a previous studies conducted by Del Gaudio, et al., Meyer, et al., and Rante $\mathrm{F}$, et al., state that there were no significance of the presence of frontal cells and the occurence of frontal rhinosinusitis but the presence of frontal cells may be a factor causing the frontal recess obstruction. $(4,7,8) \mathrm{In}$ contrast to the results of research conducted by Bent, et al., 
stating that the existence of the frontal cells can increase the incidence of frontal rhinosinusitis.(9)

Of any statistical test agger nasi cells also showed no significant relation to incidence of frontal rhinosinusitis with $p=0.289$ ( $p>0.05)$. Research conducted by Del Gaudio, et al., and Rante, et al., also found that the presence of agger nasi cells was not associated with an increased incidence of frontal rhinosinusitis. $(4,8)$ This suggests that the incidence of frontal rhinosinusitis was also not determined by the presence of agger nasi cells but the presence of agger nasi cells can cause frontal rhinosinusitis based on the degree of obstruction agger nasi cell toward the frontal recess.

The data showed from 6 UP superior attachment type, according to the frequency of UP superior attachment type 1 (UP insertion into the lamina papyracea) is the most often type with 43 sides (28.6\%), then type 6 the insertion of the UP superior to media turbinate as much as 29 (19.3\%). While type 3 and type 5 is very rare. Turgut, et al., also found that type 1 and type 2 is the most frequent and the second is the type 5 (UP superior insertion into the base of the skull).(1)

Drainage of the UP superior attachment based on type in group 1 (type $1,2,3$ ) the drainage of the frontal sinus meatus medius (medial to the superior attachment of the UP) get most frequent in the 80 sides (53.3\%), whereas in the group 2 (type $4,5,6$ ) the drainage of the frontal sinus to the ethmoid infundibulum (lateral to the superior attachment of the UP) as many as 70 sides (46.7\%). It is similar to the research conducted by Turgut, et al., of the examination of various sides, obtained that drainage group 1 was found $66 \%$ and group 2 at $34 \%$ of the slides, Landsberg and Friedman found $88 \%$ and $12 \%$ respectively. $(1,10)$ Kim, et $a l$., reported that the medial border of the frontal recess is choncal plate in $60 \%$ of cases and plates suprainfundibular (PARTI combination of UP superior and the superior bulla ethmoidalis) at 40\%.(11) While different things reported by Gaffar, et al., and Lee, et al., that the frontal sinus outflow was from the anterior side to UP at $23 \%$ and $29 \%$ respectively in the case and on the posterior side to UP at $63 \%$ and $61 \%$ respectively. $(12,13)$ The difference between these studies may be due to racial differences.(1)

In this study population, the prevalence of frontal rhinosinusitis obtained as many as 42 sides (28.0\%) of the 150 side, and as many as 32 sides $(76.2 \%)$ had type 1 drainage group (open frontal sinus medial to the UP [type 1-3]) drainage into the meatus medius, while the drainage group 2 (open frontal sinus lateral to the UP [types 4-6]) drainage into the ethmoid infundibulum as many as 10 sides $(23.8 \%)$.
Of the statistical test (chi square linear by linear association) showed significant result between events of frontal rhinosinusitis with frontal sinus drainage type with $p=0.001 \quad(p<0.05)$. Type 1 drainage group (open frontal sinus medial to the UP [types 1-3]) drainage into the meatus medius more often cause rhinosinusitis frontal when compared with group 2 (open frontal sinus lateral to the UP [types 4-6]) drainage to the ethmoid infundibulum. Turgut, et al., also did some research and found that there is a statistically significant relationship between the incidence of frontal sinusitis and frontal sinus flow system, is from the medial to the superior attachment of the UP.(1)

Sinusitis without rhinitis is rare, nasal mucosa and adjacent paranasal sinuses, and rhinitis usually precedes sinusitis. $(1,8)$ Thus, the term rhinosinusitis has begun to use than sinusitis. In the frontal sinus drainage from the medial side, where direct contact between the frontal recess and the meatus medius continue along nasal cavity making it easier for the rhinogenic infection to the frontal sinus. In frontal sinus drainage from the lateral side, UP acts as a anatomic barrier, valve between the meatus medius and frontal recess, which can result in system flow frontal sinus opens into the ethmoid infundibulum. $(1,8,11)$ This physiological process may play a role in the pathogenesis of frontal sinusitis in individuals who have a flow system to the medial of frontal sinus (group 1) should lack a anatomical barrier to prevent rising irritant or allergen and rhinogenic infection.

\section{Conclusion}

It can be concluded that the variation of the process superior adhesion uncinate type 1 is more common (28.6\%) and there is a relationship between the variation of the UP superior adhesion with frontal rhinosinusitis events, while the agger nasi cells, frontal cells and media concha bullosa was not found a relationship with the incidence of rhinosinusitis frontal. Based on the localization of the frontal sinus drainage, drainage into the medial side is more often found in the incidence of frontal rhinosinusitis than drainage to the lateral side.

\section{Acknowledgement}

Author thank Prof. Bachtiar Murtala for assistance in radiological examinations and Dr. Burhanuddin Bahar for assistance in the statistical analysis. 


\section{References}

1. Turgut S, Ercan I, Sayin I, Basak M. The relationship between frontal sinusitis and localization of the frontal sinus outflow tract: a computer-assisted anatomical and clinical study. Arch Otolaryngol Head Neck Surg.2005; 131: 518-22.

2. McLaughlin RB Jr, Rehl RM, Lanza DC. Clinically relevant frontal sinus anatomy and physiology. Otolaryngol Clin North Am. 2001; 34: 1-22.

3. Kennedy DW, Bolger WE. The paranasal sinuses: embriology, anatomy, endoscopic diagnosis, and treatment. In: Lee KJ, editors. Essential otolaringology head and neck surgery. 8th edition. New York: McGraw-Hill; 2003. p.388-410.

4. Del Gaudio JM, Hudgins PA, Venkatraman G, Beningfield A. Multiplanar computed tomographic analysis of frontal recess cells: effect on frontal isthmus size and frontal sinusitis. Arch Otolaryngol Head Neck Surg. 2005; 131: 230-5.

5. Kountakis S, Senior B, Draft W. Radiologic anatomy of the frontal sinus. In: The frontal sinus. Berlin: Springer; 2005, p.2-17

6. Seiden AM, Stankiewicz JA. Frontal sinus surgery: The state of the art. Am J Otolaryngol. 1998; 19: 183-93.

7. Meyer TK, Kocak M, Smith MM, Smith TL. Coronal computed tomography analysis of frontal cells. Am J Rhinol. 2003; 17: 163-8.

8. Rante F, Murtala B, Punagi Q. Relationship anatomical variations according kuhn frontal cells and agger nasi cells on CT scans of the sinuses paranasalis with frontal rhinosinusitis events [Thesis]. Makassar: University of Hasanuddin; 2011.

9. Bent JP, Cuilty-Siller C, Kuhn FA. The frontal cell as a cause of frontal sinus obstruction. Am J Rhinology. 1994; 8: 185-91.

10. Lansberg R, Friedman M. A computer assisted study of the nasofrontal anatomycal region. Laryngoscope. 2001; 111: 2125-30.

11. Kim KS, Kim HU, Chung IH, Lee JG, Park IY, Yoon JH. Surgical anatomy of the nasofrontal duct: anatomical and computed tomographic analysis. Laryngoscope. 2001; 111: 603-8.

12. Gaffar H, Abdel-Monem MH, Qavas MK. Frontal sinus outflow tract anatomic study. Acta Otolaryngol. 2001; 121: 305-9.

13. Lee D, Brody R, Har-El G. Outflow frontal sinus anatomy. Am J Rhinol. 1997; 11: 283-5. 